\title{
The influence of dietary fat and free sugars on liver fat content and metabolism
}

\author{
S.A. Parry ${ }^{1}$, M.E. Pichè ${ }^{1}$, T. Cornfield ${ }^{1}$, P. Dyson ${ }^{1}$, J. Francis $^{2}$, F. Mozes $^{2}$ and L. Hodson ${ }^{1}$ \\ ${ }^{1}$ Oxford Centre for Diabetes, Endocrinology and Metabolism, University of Oxford, Churchill Hospital, Oxford, OX3 \\ $7 L E$ and ${ }^{2}$ Oxford Centre for Clinical Magnetic Resonance, John Radcliffe Hospital, University of Oxford, OX3 9DU.
}

This abstract was presented as the Whole Body Metabolism Theme highlight.

Non-alcoholic fatty liver disease (NAFLD) is associated with cardiovascular disease and type 2 diabetes mellitus ${ }^{(1)}$; diet has been suggested to play a role in the development of NAFLD ${ }^{(2)}$. Whilst overfeeding excess calories as fat and/or free sugars increases liver fat content, the influence of specific macronutrients, in the context of a eucaloric diet, is unclear ${ }^{(3)}$. The aim of this study was to compare the effects of two eucaloric diets, one enriched in carbohydrate/free sugars and the other enriched in fat/saturated fatty acids (SFA) on liver fat content and metabolism in overweight males.

Ten metabolically healthy males $\left(45 \cdot 2 \pm 1 \cdot 6 \mathrm{y}, 27 \cdot 0 \pm 0.5 \mathrm{~kg} / \mathrm{m}^{2}\right)$ consumed a eucaloric high-fat (45\% total energy (TE) as fat) diet (HF) enriched with SFA (20\% TE as SFA), and a high-carbohydrate (65\% TE as carbohydrate) diet (HC) enriched with free sugars (20\% TE as free sugars) for 4-weeks, in random order, with a 7-week washout period between diets. Liver fat content was assessed before and after each dietary intervention using magnetic resonance spectroscopy (MRS). Fasting concentrations of plasma triglycerides (TG), total cholesterol and high-density lipoprotein (HDL) cholesterol were compared before and after each dietary intervention.

Body mass increased by $1.5 \pm 0.2 \mathrm{~kg}$ following HF (from $89.2 \pm 3.9 \mathrm{~kg}$ to $90.7 \pm 4.1 \mathrm{~kg} ; \mathrm{p}=0.002$ ), but was unchanged after HC (from $89.5 \pm 3.6 \mathrm{~kg}$ to $89.4 \pm 3.7 \mathrm{~kg} ; \mathrm{p}=0.587$ ). Liver fat increased by $33 \pm 19 \%$ following HF (from $5.3 \pm 1.2 \%$ to $7.6 \pm 1.7 \% ; p=0.035$ ), but remained unchanged following $\mathrm{HC}(5 \cdot 1 \pm 0.7 \%$ to $5.1 \pm 0.6 \% ; \mathrm{p}=0.909)$. Plasma total and HDL cholesterol concentrations decreased following HC (from $5.4 \pm 0.3 \mathrm{mmol} / \mathrm{L}$ to $4.7 \pm 0.3 \mathrm{mmol} / \mathrm{L}(\mathrm{p}=0.001$ ) and from $1.5 \pm 0.1 \mathrm{mmol} / \mathrm{L}$ to $1.1 \pm 0.1 \mathrm{mmol} / \mathrm{L}$ ( $\mathrm{p}<0.001$ ), respectively), but were not significantly influenced by $\mathrm{HF}(5.0 \pm 0.3 \mathrm{mmol} / \mathrm{L}$ and $4.8 \pm 0.3 \mathrm{mmol} / \mathrm{L}(\mathrm{p}=0.486) \mathrm{and} 1 \cdot 3 \pm 0 \cdot 1 \mathrm{mmol} / \mathrm{L}$ and $1.3 \pm 0.1 \mathrm{mmol} / \mathrm{L}(\mathrm{p}=0.898)$, respectively). The reduction in plasma total and HDL cholesterol concentrations following HC resulted in an increase in the total to HDL cholesterol ratio (from $3 \cdot 7 \pm 0 \cdot 1$ to $4 \cdot 2 \pm 0 \cdot 2 ; p=0 \cdot 014$ ). Fasting concentrations of plasma TAG were not influenced by either dietary intervention.

Our preliminary findings suggest that increasing dietary intakes of free sugars, in the context of a eucaloric diet have little effect on body weight and liver fat content but may increase the total:HDL cholesterol ratio. In contrast, consumption of a eucaloric diet, enriched in fat/SFA may increase liver fat content whilst having no effect on circulating lipoproteins.

1. Anstee QM, McPherson S \& Day CP (2011) BMJ 343, d3897.

2. Yasutake K, Kohjima M, Kotoh K, et al. (2014) World J Gastrointest Oncol 20, 1756-1767.

3. Parry SA \& Hodson L (2017) J Investig Med 65, 1102-1115. 